\title{
A visual identification key to Orchidaceae of Korea
}

\author{
Seon-Won Seo and Sang-Hun Oh* \\ Department of Biology, Daejeon University, Daejeon 34520, Korea \\ (Received 28 May 2017; Revised 15 June 2017; Accepted 25 June 2017)
}

\begin{abstract}
Species identification is a fundamental and routine process in plant systematics, and linguistic-based dichotomous keys are widely used in the identification process. Recently, novel tools for species identification have been developed to improve the accuracy, ease to use, and accessibility related to these tasks for a broad range of users given the advances in information and communications technology. A visual identification key is such an approach, in which couplets consist of images of plants or a part of a plant instead of botanical terminology. We developed a visual identification key for 101 taxa of Orchidaceae in Korea and evaluated its performance. It uses short statements for image couplets to avoid misinterpretations by users. The key at the initial steps (couplets) uses relatively easy characters that can be determined with the naked eye. The final steps of the visual key provide images of species and information about distributions and flowering times to determine the species that best fit the available information. The number of steps required to identify a species varies, ranging from three to ten with an average of 4.5. A performance test with senior college students showed that species were accurately identified using the visual key at a rate significantly higher than when using a linguistic-based dichotomous key and a color manual. The findings presented here suggest that the proposed visual identification key is a useful tool for the teaching of biodiversity at schools, for the monitoring of ecosystems by citizens, and in other areas that require rapid, easy, and accurate identifications of species.
\end{abstract}

Keywords: accuracy, biodiversity, education, identification, monitoring, photograph, Orchidaceae

A method that allows the accurate identification of plant species is a fundamental process in plant systematics (Simpson, 2010). Such a method provides a basic tool not only for inventory purposes and for a clear understanding of the phylogenetic relationships of plant taxa, but also for the conservation, management, and sustainable usage of plant resources. A dichotomous key is the method commonly used for species identification, and this tool is typically available in many taxonomic revisions and local floristic treatments (Ohwi, 1965; Gleason and Cronquist, 1991; Cope, 2001; Lawrence and Hawthorne, 2006; Park, 2007).

Recently, new approaches have been developed to facilitate species identification using computer programs. The interactive key is one such tool, with which users initially choose any characters which are readily available and select the appropriate character state given by the key. The basic algorithm of an interactive key is to search for a taxon by eliminating taxa that do not have the selected character state. The flexibility of choosing characters at the beginning and the subsequent steps not predetermined by the key make interactive keys easily accessible to non-specialists. Several programs have been developed for various taxa, such as Intkey for DELTA System (Dalwitz et al., 1993; Coleman et al., 2010), ActKey (Brach and Song, 2005), Dryades (Nimis et al., 2012), Linnaeus NG (Doorenweerd et al., 2014), FRIDA (FRiendly Identification) (Martellos and Nimis, 2015; Martellos et al., 2016), and WEBiKEY (Attigala et al., 2016).

A visual identification key is an approach which utilizes electronic keys with images of plants or a part of a plant for couplets rather than technical terminology (Kirchoff et al., 2011). A broad range of users, including non-specialists who are unfamiliar with botanical terminology, may find it helpful to use a visual identification key to identify species. With advances in information and communications technology and

\footnotetext{
*Author for correspondence: soh42@dju.kr
} 
the increasing volume of plant images, developing a visual identification key to a taxonomic group has become relatively simple. Kirchoff et al. (2011) provided several principles of the generation of a visual identification key using the case of the Fagaceae of the southeastern United States. The performance of a web-based electronic identification key is considered to be better for users than that of a traditional dichotomous key based on text (dela Cruz et al., 2012; but see Stagg et al., 2015). Nonetheless, it remains unknown to what extent a visual key can help to identify species.

The Orchidaceae consist of approximately 25,000 species and is one of the largest families of angiosperms (Chase, 2005). The Orchidaceae is widely distributed throughout the world, occupying diverse vegetation types from tropical rain forest to tundra and with the highest species diversity in the tropics (Atwood, 1986; Dressler, 1993). The family is well known for its economic importance in horticulture, the fragrance industry, medicine, spices, and in the food industry (Dressler, 1993; Eltz et al., 2007; Kasulo et al., 2009; Gutiérrez, 2010). Many wild orchids are under the threat of extinction globally owing to habitat loss, over-collection, and climate changes (Swarts and Dixon, 2009), and this unfortunate trend of biodiversity loss is especially critical in Korea given the long tradition of the ornamental use of orchids. The Orchidaceae represent an important family in the conservation biology in Korea, accounting for approximately $3.2 \%$ of vascular plants at the species level in Korea (Park, 2007), i.e., 97 species (103 taxa) in 42 genera (Lee, 2011). Of the 77 vascular plant species on the Endangered Species List of Korea managed by the Korean Ministry of Environment (Korean; http://species.nibr.go.kr), 18 species $(23 \%)$ belong to the Orchidaceae, illustrating the important status of Korean orchids in conservation biology.

Classification of the Orchidaceae relies mainly on floral characteristics, as in many other angiosperms, and it is very difficult to recognize a species without flowers (Dressler, 1993). Floral structures in the Orchidaceae are highly specialized such that non-specialists who do not have knowledge of the diversity of the morphological features of these plants may have difficulty using traditional dichotomous keys due to the complex terminology involved. Thus the Orchidaceae family serves as an excellent case with which to test the performance of a new identification tool to determine if the usage of a visual identification key may improve the accuracy of and time required for species identification of the Orchidaceae by non-specialists.

The aim of this study is to develop a framework for a visual identification key to the Orchidaceae in Korea and to evaluate the performance of the key in terms of accuracy and time spent when university student users use it to identify species.

\section{Materials and Methods}

\section{Taxa}

All taxa of the Orchidaceae known to occur in Korea (Lee, 2011) were included in this study (Appendix 1), except for Cymbidium ensifolium (L.) Sw. and Platanthera mandarinorum Rchb. f. subsp. neglecta (Schltr.) K. Inoue. Taxonomic identities of the species and distribution in Korea are uncertain. Thus, a total of 101 taxa were included. For those species of which flower colors are polymorphic within the species, different color types were separately represented. As a result, the following 18 taxa were represented twice in the visual key: Cypripedium guttatum Sw., Cypripedium macranthos Sw., Galearis cyclochila (Franch. \& Sav.) Soó, Amitostigma gracile (Blume) Schltr., Neolindleya camtschatica (Cham.) Nevski, Gymnadenia conopsea (L.) R. Br., Neottianthe cucullata (L.) Schltr., Spiranthes sinensis (Pers.) Ames, Pogonia japonica Rchb. f., Pogonia minor (Makino) Makino, Goodyera maximowicziana Makino, Bletilla striata (Thunb.) Rchb. f., Liparis nervosa (Thunb.) Lindl., Liparis japonica (Miq.) Maxim., Liparis krameri Franch. \& Sav., Liparis makinoana Schltr., Liparis koreojaponica Tsutsumi, T. Yukawa, N. S. Lee, C. S. Lee \& M. Kato, and Calypso bulbosa (L.) Oakes. All photographs were taken in the wild, except for that of Sedirea japonica (Rich. f.) Garay \& H. R. Sweet, of which cultivated materials were taken. A Nikon digital camera (model D810) with a NIKORR $66 \mathrm{~mm}$ (Nikon, Tokyo, Japan), $105 \mathrm{~mm}$, or 24-70 $\mathrm{mm}$ lens was used to generate the photographic images.

\section{Construction of the visual key}

We followed the general guideline provided in Kirchoff et al. (2011). A photograph of each species was printed and then sorted into two or three groups with common characteristics. These groupings were hierarchically repeated within each group until three to five images remained. The characteristics used in each grouping were easily observed and determined by the naked eye or at $10 \times$ magnification. A representative close-up image of the group or a composite image was prepared for the couplets with an additional short statement for the image. Unlike the visual identification key of Kirchoff et al. (2011), we added a short statement for each image to avoid misinterpretations of image by users. At the final steps of the key, three photographs along with information about the distribution and flowering time of the species are provided such that users may determine the correct species with a minimal amount of text. 
Web pages were created using Hypertext Markup Language (HTML) to use the visual identification key in a web browser. Each web page shows two or three images (representing couplets). Selection of one image leads to a subsequent couplet set. The web pages were stored on a local storage medium. The package of web pages (compressed form, ca. $210 \mathrm{MB}$ ) is available upon request.

\section{Performance test}

The accuracy and efficiency of the visual identification key were assessed in the Plant Systematics laboratory class at Daejeon University. As many as 25 senior students participated in the assessment, all of whom had basic knowledge of plant biology at the level of a general biology course offered at a lower level. The students represent potential users who do not have in-depth knowledge about plant diversity. A set of photographs of five species of Orchidaceae (Cypripedium macranthos, Goodyera biflora (Lindl.) Hook. f., Neolindleya camtschatica, Cephalanthera erecta var. oblanceolata N. Pearce \& P. J. Cribb, and Dendrobium moniliforme (L.) Sw.) was provided to the students. The photograph specimens were taken from independent resources and do not appear in the visual key. The students attempted to identify the species using three different methods: (1) the visual identification key web pages, (2) the dichotomous key in Lee et al. (2007) translated into Korean, and (3) a color illustrated floristic manual (Lee, 2003). Each performance test was carried out on separate dates separated by at least a week. Some students did not participate in the latter two tests. Twenty-three students participated in Test II, and 16 students in Test III. The assessment using the visual identification key (test I) was completed on March 9, 2017, at a computer laboratory on campus where the package of local web pages was installed for the test. The second test (test II) that used the dichotomous key was carried out on March 16, 2017, and the third test (test III) with the color manual was conducted on March 30, 2017. In the third test, three new species (Oreorchis patens (Lindl.) Lindl., Amitostigma gracile, and Bletilla striata (Thunb.) Rchb. f.) were included for an independent assessment of the performance. The number of students who identified the orchid specimens accurately and the time spent on identification were recorded.

\section{Results}

The visual identification key to Orchidaceae in Korea (Fig. 1) was developed as a case with which to design a visual key to the flora of Korea. A total of 101 taxa can be identified using the key. Distinct floral color forms in 18 taxa were separately considered to represent the variation. Thirteen characters were used in the visual key (Table 1). The characters could be categorized into three categories: habit, leaves, and reproductive organs. Some characters were used multiple times in the visual key. For example, the couplet of flower color was used eight times, the number of leaves seven times, the number of flowers six times, and the leaf length four times. The remaining characters were used once.

The visual couplets at the initial steps used relatively easy characters that can be determined with the naked eye. For example, the first couplet divides Korean orchids into two groups: plants with leaves and those without leaves. Final steps of the visual key do not utilize a visual couplet. Instead, images of species along with information about the distribution and flowering time were provided such that users can identify the specimen that best fits the information. The number of steps required to identify a species varies, ranging from three to ten steps with an average of 4.5 steps.

The performance with the visual identification key was better than that using a traditional taxonomic key and that by screening the floristic manual (Table 2). The percentage of students who accurately identified the set of species correctly ranged from $56 \% \quad(\mathrm{n}=14 ;$ Cephalanthera erecta var. oblanceolata $)$ to $96 \%(\mathrm{n}=24$; Cypripedium macranthos and Neolindleya camtschatica) with the visual identification key. Students were asked to use the taxonomic key (Lee et al., 2007) to the generic level, as no students determined the species with the taxonomic key. The percentage of students who determined the correct genus in the second test ranged from $30.4 \%(\mathrm{n}=7$; Goodyera) to $73.9 \%(\mathrm{n}=17$; Cypripedium and Dendrobium). In the third test, students appeared to learn the names of the species through the previous two tests. For example, one student identified Cephalanthera erecta var. oblanceolata using Lee (2003), in which the taxon was not described. Except for this species, the percentage of students who correctly identified the four test species used in the previous tests ranged from $43.8 \%(\mathrm{n}=7$; Goodyera biflora $)$ to $100 \%(\mathrm{n}=16$; Cypripedium macranthos and Neolindleya camtschatica). Three additional test species were added to examine the level of accurate identification without knowledge from earlier experience. The percentage of students who correctly identified the three additional test specimens ranged from 25\% (Oreorchis patens) to $87.5 \%$ (Bletilla striata).

The time for the correct identification of the specimens did not show significant differences among the three different methods (Table 2). For Cypripedium macranthos, the average time for identification using the visual key (Test I) was shorter (average of $33 \mathrm{~s}$ ) compared to when using the dichotomous key 

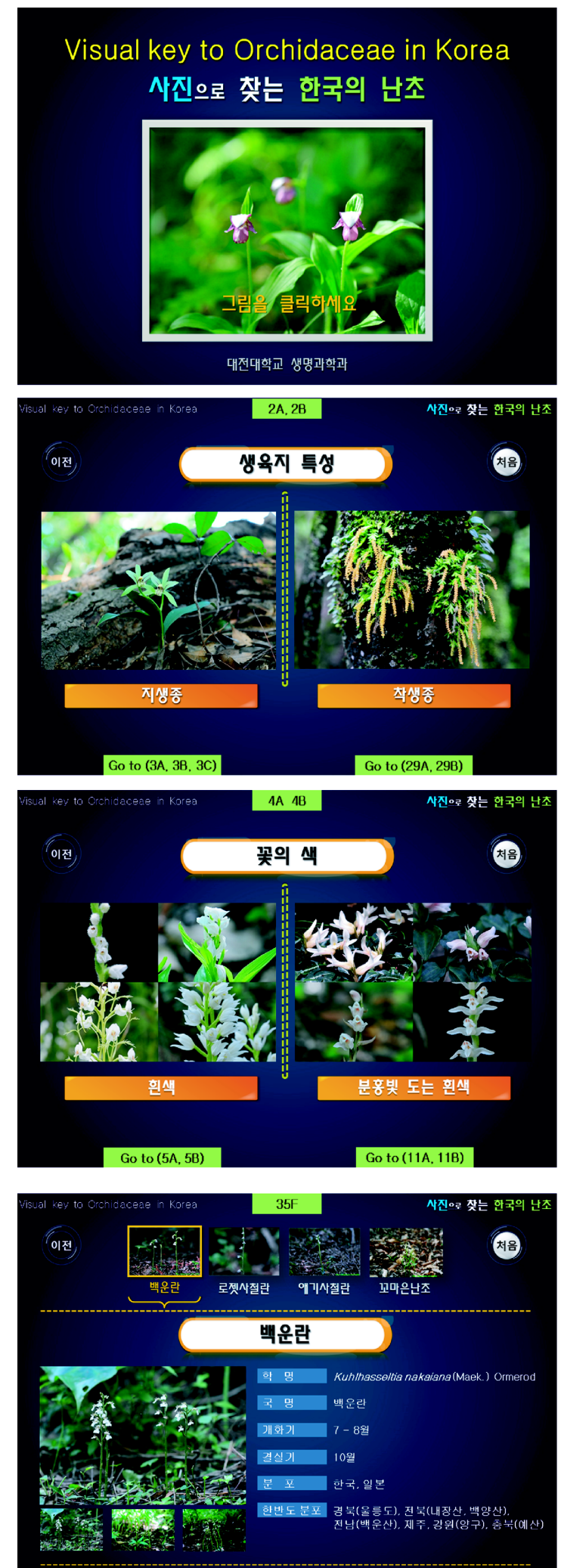
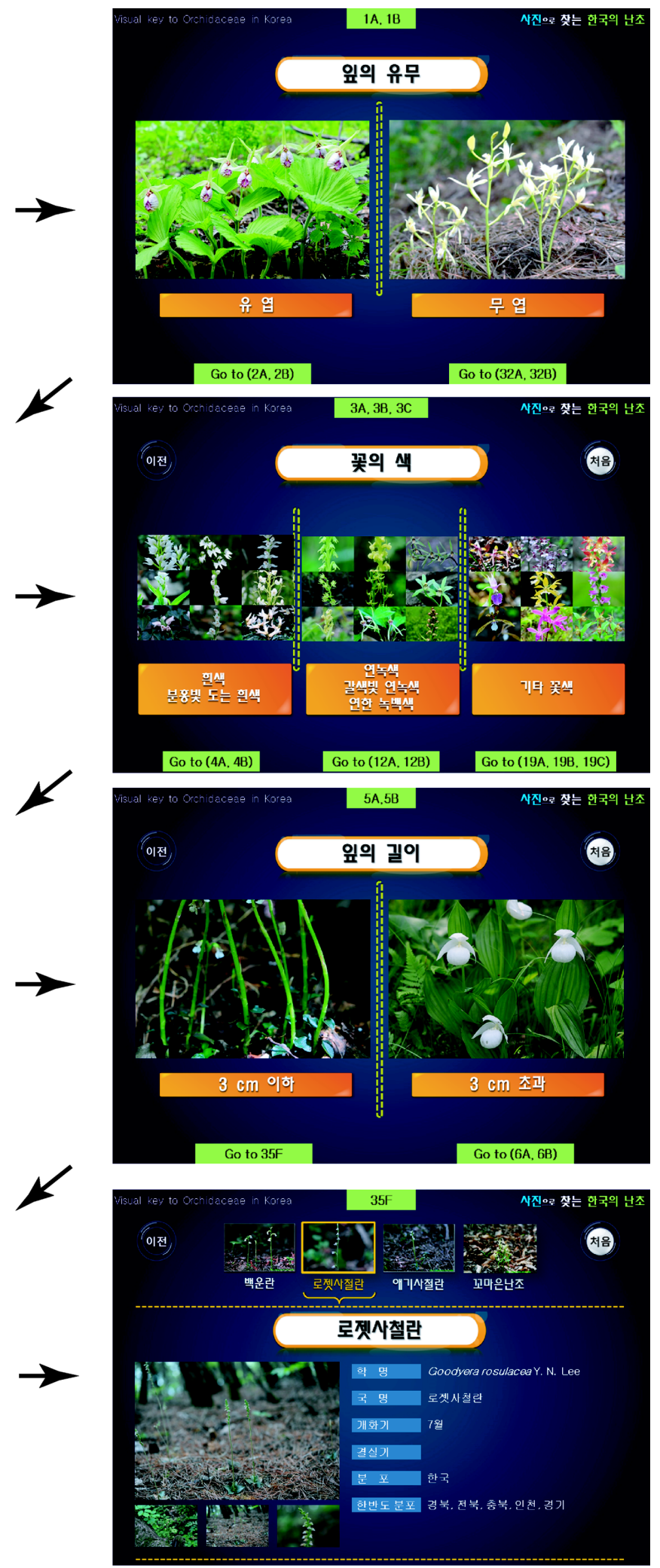

Fig. 1. Exemplar pages of the visual identification key to the Orchidaceae in Korea. Couplet number is placed in upper center and direction to the next couplet if selected is indicated just below the lead. The last step does not use couplets but instead allows users to determine a species by examining photographs and other biological information. When Goodyera rosulacea Y. N. Lee is to be identified, users should select "leaves present," "terrestrial," "flowers white or pinkish white," "flowers white," and "leaves less than $3 \mathrm{~cm}$ long." 
Table 1. Characters and character states used in the visual identification key to the Orchidaceae in Korea. Some characters were used more than once in different couplets.

\begin{tabular}{llcc}
\hline \hline \multicolumn{1}{c}{ Category } & \multicolumn{1}{c}{ Character } & Character states & Number of usage in key \\
\hline Habit & Habitat & Terrestrial vs. epiphytic & 1 \\
& Stem growth form & Prostrate vs. erect & 1 \\
& Plant height & Measurement & 1 \\
& Presence of leaves & Present vs. absent & 1 \\
Leaves & Leaf attachment & Sheathing vs. not sheathing & 1 \\
& Number of leaves & Measurement & 4 \\
& Leaf length & Measurement & 1 \\
Inflorescence & Stipe length & Measurement & 1 \\
& Flower arrangement & Spiral vs. not spiral & 8 \\
& Flower color & Color & 6 \\
& Flower number & Measurement & 1 \\
\hline
\end{tabular}

Table 2. Summary of the number of students who accurately identified the specimens and the average time (minimum-maximum) spent on identification. Test I = assessments with the visual identification key to Orchidaceae in Korea; Test II = identification of specimens at the generic level using Lee et al. (2007); Test III = identification of species using Lee (2003). Twenty-five students participated in Test I, 23 students in Test II, and 16 students in Test III. NT = not tested.

\begin{tabular}{|c|c|c|c|c|c|c|}
\hline \multirow{2}{*}{ Species } & \multicolumn{3}{|c|}{$\begin{array}{c}\text { Number of students who accurately identified } \\
\text { specimens }(\%)\end{array}$} & \multicolumn{3}{|c|}{$\begin{array}{l}\text { Average time (s) for accurate identification } \\
\text { (min-max) }\end{array}$} \\
\hline & $\begin{array}{c}\text { Test I } \\
(\mathrm{n}=25)\end{array}$ & $\begin{array}{c}\text { Test II } \\
(\mathrm{n}=23)\end{array}$ & $\begin{array}{l}\text { Test III } \\
(\mathrm{n}=16)\end{array}$ & $\begin{array}{c}\text { Test I } \\
(\mathrm{n}=25)\end{array}$ & $\begin{array}{c}\text { Test II } \\
(\mathrm{n}=23)\end{array}$ & $\begin{array}{l}\text { Test III } \\
(\mathrm{n}=16)\end{array}$ \\
\hline $\begin{array}{l}\text { Cephalanthera erecta } \\
\text { var. oblanceolata }\end{array}$ & $14(56)$ & $9(39.1)$ & $1(6.3)$ & $\begin{array}{c}203 \\
(30-360)\end{array}$ & $\begin{array}{c}79 \\
(10-240)\end{array}$ & 80 \\
\hline $\begin{array}{l}\text { Cypripedium } \\
\text { macranthos }\end{array}$ & $24(96)$ & $17(73.9)$ & $16(100)$ & $\begin{array}{c}33 \\
(17-60)\end{array}$ & $\begin{array}{c}51 \\
(2-180)\end{array}$ & $\begin{array}{c}96 \\
(1-340)\end{array}$ \\
\hline $\begin{array}{l}\text { Dendrobium } \\
\text { moniliforme }\end{array}$ & $18(72)$ & $17(73.9)$ & $14(87.5)$ & $\begin{array}{c}78 \\
(38-110)\end{array}$ & $\begin{array}{c}56 \\
(2-124)\end{array}$ & $\begin{array}{c}86 \\
(20-190)\end{array}$ \\
\hline Goodyera biflora & $22(88)$ & $7(30.4)$ & $7(43.8)$ & $\begin{array}{c}125 \\
(13-249)\end{array}$ & $\begin{array}{c}95 \\
(50-320)\end{array}$ & $\begin{array}{c}67 \\
(10-200)\end{array}$ \\
\hline $\begin{array}{l}\text { Neolindleya } \\
\text { camtschatica }\end{array}$ & $24(96)$ & $12(52.2)$ & $16(100)$ & $\begin{array}{c}85 \\
(38-229)\end{array}$ & $\begin{array}{c}72 \\
(38-120)\end{array}$ & $\begin{array}{c}84 \\
(5-260)\end{array}$ \\
\hline Amitostigma gracile & NT & NT & $10(62.5)$ & NT & NT & $\begin{array}{c}99 \\
(20-209)\end{array}$ \\
\hline Bletilla striata & NT & NT & $14(87.5)$ & NT & NT & $\begin{array}{c}139 \\
(36-300)\end{array}$ \\
\hline Oreorchis patens & NT & NT & $4(25)$ & NT & NT & $\begin{array}{c}50 \\
(12-80)\end{array}$ \\
\hline
\end{tabular}

(Test II; $51 \mathrm{~s}$ ) and the floristic manual (Test III; $96 \mathrm{~s}$ ). In another case, such as Goodyera biflora, students identified the species much more rapidly when they screened the manual (Test III; average of $67 \mathrm{~s}$ ) compared to when they used the visual key (Test I; $125 \mathrm{~s}$ ) and the dichotomous key (Test II; $95 \mathrm{~s}$ ).

\section{Discussion}

The visual identification key to the Korean Orchidaceae family developed in this study is the first comprehensive taxonomic key based on images in Korea. The web pages 
which facilitated the use of the visual identification key were run from local storage in our study. This approach should be useful when the key is converted into a web-based program in that users can then access the key via the Internet. We expect that the development of the visual identification key for other groups or for the entire flora of Korea will be possible as digital images of plants become more widely available from various resources. Further development of the on-line visual identification keys is therefore necessary.

The visual key to Orchidaceae developed in this study is similar to a traditional dichotomous key in that it has a set of couplets predetermined by the developer. However, the visual key is very efficient in terms of the number of characters used in the key and the performance of the keys by users, especially those who are non-specialists with regard to Orchidaceae. Our visual key uses only 13 characters (Table 1), while the dichotomous key to Orchidaceae (Lee et al., 2007) uses more than 50 characters. In general, traditional dichotomous keys use one or more characters in a couplet and represent classifications in many cases (e.g., Gleason and Cronquist, 1991). The key to the species of Orchidaceae in Lee (2007) is in accordance with the traditional keys in that it utilizes two steps to identify a species; it initially leads to a genus, and a subsequent dichotomous key within the genus then leads to a species if the genus is not monotypic. The visual key does not consider higher levels of classification of Orchidaceae, such as genus or subfamily, and it directly leads to the species.

The advantage of the visual key is its easy usage by general users who do not necessarily have knowledge of botanical terminology (Kirchoff, 2011). The characters used in our visual key are relatively simple and thus are easily understood by users. Anatomical structures of flowers are important in the classification of Orchidaceae, but our visual key is designed to identify a species without knowledge of such characteristics. Floral characters in Orchidaceae are highly specialized (Atwood, 1986; Dressler, 1993), which makes it difficult for most users to understand the characters and to determine correct character states. In our survey, students had difficulties with their interpretation of couplets, such as incumbent vs. erect anthers and lip morphology, in the traditional dichotomous key (Lee et al., 2007). Identification of the five orchid specimens at the genus level (Test II) (Table 2) showed a low level of performance compared with the visual key (Test I).

Our survey showed that the rate of accurately identifying a species using the visual key was significantly higher when the student used the visual key (Table 2). Our results are consistent with those of previous work (dela Cruz et al., 2012). More students identified the correct species for four of five specimens with the visual key compared to the traditional dichotomous key. For Cypripedium macranthos and Neolindleya camtschatica, most students determined the correct identification with the visual key, while the performances with the dichotomous key were low. For Dendrobium moniliforme, the percentages of students who achieved correct identification were similar to one another. Performance with the visual key was low when students attempted to identify Cephalanthera erecta var. oblanceolata; $56 \%$ of the students correctly identified this species. Many students identified it as Cephalanthera erecta var. erecta or C. longibracteata. Cephalanthera erecta var. oblanceolata differs from the two taxa by the spurless lip. Our visual key shows the difference when users reach the final steps, but many users may not recognize the character for identification. This suggests that an additional process is necessary to enhance the accuracy of the visual key, such as showing diagnostic characters at the species page.

The rate of accurately identifying a species using a color manual (Test III) for the five species common in all tests is high (Table 2). Each test was performed on different dates, but it appears that the students may have learned the names of the species from the preceding tests. One student identified Cephalanthera erecta var. oblanceolata, but this taxon was not described in Lee (2003), indicating the effect of education. When asked to identify new species using the color manual, the rate of accurately identifying a species fell to $25 \%$. Identification of a specimen using a color manual requires users to find the image most similar to the species in the manual. It also requires the specification of the diagnostic characteristics from the image and description to accurately identify a species. When a species does not show obvious characteristics, such as Oreorchis patens in our study, students have difficulties in identification. But, when a species show distinct characteristics, such as Bletilla striata with large flowers and bright color, many students could determine a species without difficulty (Table 2).

The use of photographic images in the keys and of webbased interactive keys greatly enhances the use of the taxonomic keys. The integration of linguistic-based characters and diagnosis in the visual keys should increase the ease of use and accuracy of this method. This will provide a useful tool for biodiversity education at schools, the monitoring of ecosystems by citizens, and in other areas that require rapid, easy, and accurate identifications of species.

\section{Acknowledgments}

We are grateful to students taking the Plant Systematics course in 2017 at Daejeon University for their participation in 
the performance test of the visual key. We also thank SangWook Han, Yoon Kyoung Choi, and Hwa-Jung Suh for their help with the construction of the key. We are grateful for helpful comments from two anonymous reviewers. This work was supported by a research grant from the National Research Foundation of Korea, NRF 2016R1D1A1B03934663.

\section{Literature Cited}

Attigala, L., N. I. de Silva and L. G. Clark. 2016. Simple webbased interactive key development software (WEBiKEY) and an example key for Kuruna (Poaceae: Bambusoideae). Applications in Plant Sciences 4: 1500128.

Atwood, J. T. 1986. The size of the Orchidaceae and the systematic distribution of epiphytic orchids. Selbyana 9: 171-186.

Brach, A. R. and H. Song. 2005. ActKey: A web-based interactive identification key program. Taxon 54: 1041-1046.

Chase, M. W. 2005. Classification of Orchidaceae in the age of DNA data. Curtis's Botanical Magazine 22: 2-7.

Coleman, C. O., J. K. Lowry and T. Macfarlane. 2010. DELTA for beginners: An introduction into the taxonomy software package DELTA. ZooKeys 45: 1-75.

Cope, E. A. 2001. Muenscher's Keys to Woody Plants: An Expanded Guide to Native and Cultivated Species. Cornell University Press, Ithaca, NY, 337 pp.

dela Cruz, T. E. E. M., M. V. B. Pangilinan and R. A. Litao. 2012. Printed identification key or web-based identification guide: An effective tool for species identification? Journal of Microbiology and Biology Education 13: 180-182.

Dalwitz, M. J., T. A. Paine and E. J. Zurcher. 1993 onwards. User's guide to the DELTA system: A general system for processing taxonomic descriptions, 4th ed. Retrieved Jun. 2, 2017, available from: http://delta-intkey.com/.

Doorenweerd, C., M. M. van Haren, M. Schermer, S. Pieterse and E. J. van Nieukerken. 2014. A Linnaeus $\mathrm{NG}^{\mathrm{TM}}$ interactive key to the Lithocolletinae of North-West Europe aimed at accelerating the accumulation of reliable biodiversity data (Lepidoptera, Gracillariidae). ZooKeys 422: 87-101.

Dressler, R. L. 1993. Phylogeny and Classification of the Orchid Family. Dioscorides Press, Portland, OR, 314 pp.

Eltz, T., Y. Zimmermann, J. Haftmann, R. Twele, W. Francke, J. J. G. Quezada-Euan and K. Lunau. 2007. Enfleurage, lipid recycling and the origin of perfume collection in orchid bees. Proceedings of the Royal Society B: Biological Sciences 22: 2843-2848.
Gleason, H. A. and A. Cronquist. 1991. Manual of Vascular Plants of Northeastern United States and Adjacent Canada. The New York Botanical Garden, New York, 993 pp.

Gutiérrez, R. M. P. 2010. Orchids: A review of uses in traditional medicine, its phytochemistry and pharmacology. Journal of Medicinal Plants Research 4: 592-638.

Kasulo, V., L. Mwabumba and C. Munthali. 2009. A review of edible orchids in Malawi. Journal of Horticulture and Forestry 1: 133-139.

Kirchoff, B. K., R. Leggett, V. Her, C. Moua, J. Morrison and C. Poole. 2011. Principles of visual key construction: With a visual identification key to the Fagaceae of the southeastern United States. AoB Plants 2011: plr005.

Lawrence, A. and W. Hawthorne. 2006. Plant Identification: Creating User-Friendly Field Guides for Biodiversity Management. Earthscan, London, 268 pp.

Lee, N. S. 2011. Illustrated Flora of Korean Orchids. Ewha Womans University Press, Seoul, 345 pp. (in Korean)

Lee, N. S., W.-B. Lee, B.-H. Choi and K.-W. Tae. 2007. Orchidaceae. In The Genera of Vascular Plants of Korea. Park, C.-W. (ed.), Academy Publishing Co., Seoul. Pp. 1339-1376.

Lee, T. B. 2003. Coloured Flora of Korea. Hyangmunsa, Seoul, 910 pp. (in Korean)

Martellos, S. and P. L. Nimis. 2015. From local checklists to online identification portals: A case study on vascular plants. PLoS ONE 10: e0120970.

Martellos, S., L. Ukosich and M. Avian. 2016. JellyWeb: An interactive information system on Scyphozoa, Cubozoa and Staurozoa. ZooKeys 554: 1-25.

Nimis, P. L., R. Riccamboni and S. Martellos. 2012. Identification keys on mobile devices: The Dryades experience. Plant Biosystems 146: 783-788.

Ohwi, J. 1965. Flora of Japan. Smithsonian Institution, Washington, D.C., 1067 pp.

Park, C.-W. (ed.) 2007. The Genera of Vascular Plants of Korea. Academy Publishing Co., Seoul, 1482 pp.

Simpson, M. G. 2010. Plant Systematics. 2nd ed. Elsevier, Amsterdam, $740 \mathrm{pp}$.

Stagg, B. C., M. E. Donkin and A. M. Smith. 2015. Bryophytes for beginners: The usability of a printed dichotomous key versus a multi-access computer-based key for bryophyte identification. Journal of Biological Education 49: 274-287.

Swarts, N. D. and K. W. Dixon. 2009. Terrestrial orchid conservation in the age of extinction. Annals of Botany 104: 543556. 


\section{Appendix 1.}

List of taxa included in the visual identification key to Orchidaceae in Korea. Taxa that have polymorphic floral colors were included as separate taxa and are indicated here with asterisks.

Amitostigma gracile (Blume) Schltr.*, Bletilla striata (Thunb.) Rchb. f.*, Bulbophyllum drymoglossum Maxim. ex Okubo, Bulbophyllum inconspicuum Maxim., Calanthe aristulifera Rchb. f., Calanthe bicolor Lindl., Calanthe discolor Lindl., Calanthe reflexa Maxim., Calanthe striata Lindl., Calypso bulbosa (L.) Oakes*, Cephalanthera erecta (Thunb. ex Murray) Blume var. erecta, Cephalanthera erecta var. oblanceolata N. Pearce \& P. J. Cribb, Cephalanthera falcata (Thunb. ex A. Murray) Blume, Cephalanthera longibracteata Blume, Cephalanthera longifolia (L.) Fritsch, Cephalanthera subaphylla Miyabe \& Kudô, Chamaegastrodia shikokiana Makino \& F. Maek., Cleisostoma scolopendrifolium (Makino) Garay, Corallorhiza trifida Chatel., Cremastra appendiculata (D. Don) Makino var. variabilis (Blume) I. D. Lund., Cremastra unguiculata (Finet) Finet, Cymbidium goeringii (Rchb. f.) Rchb. f., Cymbidium kanran Makino, Cymbidium lancifolium Hook. var. aspidistrifolium (Fukuy.) S. S. Ying, Cymbidium macrorhizon Lindl., Cymbidium nagifolium Masam., Cypripedium calceolus L., Cypripedium guttatum Sw.*, Cypripedium japonicum Thunb., Cypripedium macranthos Sw.*, Cypripedium shanxiense X. Q. Chen, Cypripedium $\mathrm{x}$ ventricosum Sw., Cyrtosia septentrionalis (Rchb. f.) Garay, Dactylorhiza viridis (L.) R. H. Bateman, Pridgeon \& M. W. Chase var. coreana (Nakai) N. S. Lee, Dactylorhiza viridis (L.) R. H. Bateman, Pridgeon \& M. W. Chase var viridis, Dendrobium moniliforme (L.) Sw., Epipactis papillosa Franch. \& Sav., Epipactis thunbergii A. Gray, Epipogium aphyllum Sw., Galearis cyclochila (Franch. \& Sav.) Soó*, Gastrochilus japonicus (Makino) Schltr., Gastrochilus matsuran (Makino) Schltr., Gastrodia elata Blume, Gastrodia pubilabiata Sawa, Goodyera biflora (Lindl.) Hook. f., Goodyera maximowicziana Makino*, Goodyera repens (L.) R. Br., Goodyera rosulacea Y. N. Lee, Goodyera schlechtendaliana Rchb. f., Goodyera velutina Maxim. ex Regel, Goodyera x tamnaensis N. S. Lee, S. H. Yeau \& C. S. Lee, Gymnadenia conopsea (L.) R. Br.*, Habenaria chejuensis Y. Lee \& K. Lee, Habenaria cruciformis Ohwi, Habenaria flagellifera (Maxim.) Makino, Habenaria iyoensis Ohwi, Habenaria linearifolia Maxim., Habenaria radiata (Thunb.) Spreng., Herminium lanceum var. longicrure (C. Wright) H. Hara, Herminium monorchis (L.) R. Br., Kuhlhasseltia nakaiana (F. Maek.) Ormerod, Lecanorchis japonica Blume, Lecanorchis kiusiana Tuyama var. kiusiana, Lecanorchis kiusiana Tuyama var. suginoana (Tuyama) T. Hashim., Liparis auriculata Blume ex Miq., Liparis japonica (Miq.) Maxim.*, Liparis koreojaponica Tsutsumi, T. Yukawa, N. S. Lee, C. S. Lee \& M. Kato*, Liparis krameri Franch. \& Sav.*, Liparis kumokiri F. Maek., Liparis makinoana Schltr.*, Liparis nervosa (Thunb.) Lindl.*, Liparis pterosepala N. S. Lee, C. S. Lee \& K. S. Lee, Liparis yongnoana N. S. Lee, C. S. Lee \& K. S. Lee, Malaxis monophyllos (L.) Sw., Neofinetia falcata (Thunb.) Hu, Neolindleya camtschatica (Cham.) Nevski*, Neottia acuminate Schltr., Neottia kiusiana T. Hashim \& Hatus., Neottia papiligera Schltr., Neottia pinetorum (Lindl.) Szlach., Neottianthe cucullata (L.) Schltr.*, Nervilia nipponica Makino, Oberonia japonica (Maxim.) Makino, Oreorchis coreana Finet, Oreorchis patens (Lindl.) Lindl., Platanthera chlorantha (Custer) Rchb. f., Platanthera chorisiana (Custer) Rchb. f., Platanthera fuscescens (L.) Kraenzl., Platanthera hologlottis Maxim., Platanthera japonica (Thunb. ex Murray) Lindl., Platanthera mandarinorum Rchb. f. subsp. mandarinorum, Platanthera mandarinorum Rchb. f. subsp. maximowicziana (Schltr.) K. Inoue, Platanthera mandarinorum Rchb. f. subsp. ophrydioides (F. Schmidt) K. Inoue, Platanthera ussuriensis (Regel \& Maack) Maxim., Pogonia japonica Rchb. f.*, Pogonia minor (Makino) Makino*, Ponerorchis joo-iokiana (Makino) Soó, Sedirea japonica (Rchb. f.) Garay \& H. R. Sweet, Spiranthes sinensis (Pers.) Ames*, Thrixspermum japonicum (Miq.) Rchb. f., Tipularia japonica Matsum. 